\title{
CAPÍTULO 40: MICROENCAPSULAÇÃO DOS EXTRATOS DE ERVA MATE (Ilex paraguariensis) EM DUAS MATRIZES E SUAS ESTABILIDADES DURANTE A DIGESTÃO IN VITRO
}

\author{
CHAPTER 40: MICROENCAPSULATION OF MATE EXTRACTS (Ilex \\ paraguariensis) IN TWO MATRICES AND THEIR STABILITIES DURING \\ IN VITRO DIGESTION
}

Vanesa Gesser Correa ${ }^{1}$, Bruna Kaori Tabada ${ }^{2}$, Kamila de Cássia Spack ${ }^{3}$, Rúbia Carvalho Gomes Corrêa ${ }^{4}$, Rosane Marina Peralta ${ }^{5}$

\begin{abstract}
Resumo
A erva mate (Ilex paraguariensis) é uma árvore nativa da América do Sul e suas folhas são utilizadas no preparo de infusões ricas em compostos fenólicos antioxidantes, principalmente ácido cafeico e ácidos clorogênicos. Estudos prévios tem mostrado uma redução da atividade antioxidante após a digestão gastrointestinal in vitro. O objetivo deste trabalho foi avaliar uma provável proteção dos bioativos dos extratos da erva mate pelo processo de microencapsulação. Microcápsulas dos extratos de erva mate foram elaboradas utilizando maltodextrina e alginato de sódio. A estabilidade ao processo de digestão gastrointestinal in vitro dos extratos livre e microencapsulados foi avaliada utilizando-se como parâmetros o teor em compostos fenólicos totais e a atividade antioxidante pelo método FRAP. Os resultados obtidos sugerem que as duas microencapsulações mostraram uma discreta tendência de proteção dos bioativos antioxidantes dos extratos quando avaliados pelo método dos fenólicos totais e pelo método FRAP.
\end{abstract}

Palavras-Chave: atividade antioxidante, digestão in vitro, erva mate, estabilidade, microencapsulação

\begin{abstract}
Yerba mate (Ilex paraguariensis) is a tree native of South America and its leaves are used in the preparation of infusions rich in antioxidant phenolic compounds, mainly caffeic acid and chlorogenic acids. Previous studies have shown a reduction in antioxidant activity after in vitro gastrointestinal digestion. The objective of this work was to evaluate a probable protection of bioactive extracts of yerba mate by the microencapsulation process. Yerba mate extract microcapsules were carried out using maltodextrin and sodium alginate. The stability to the in vitro gastrointestinal digestion process of free and microencapsulated extracts was evaluated using the content of total phenolic compounds and the antioxidant activity by the FRAP method as parameters. The results obtained suggest that the two microencapsulations showed a discrete tendency to protect the bioactive of the extracts when evaluated by total phenolic contents and by the FRAP method.
\end{abstract}

Keywords: antioxidant activity, in vitro digestion, mate herb, stability, microencapsulation.

\footnotetext{
${ }^{1}$ Pós-graduação em Ciência de Alimentos (PPC), Universidade Estadual de Maringá, :vanesagesser@gmail.com

${ }^{2}$ Engenharia de alimentos, Universidade Estadual de Maringá, bruna.kaori3@ gmail.com

${ }^{3}$ Pós-graduação em Ciência de Alimentos (PPC), Universidade Estadual de Maringá, kamilaspacki@outlook.com

${ }^{4}$ Instituto Cesumar de Ciência, Tecnologia e Inovação, UniCesumar. rubia_engalim@ @otmail.com

${ }^{5}$ PPC e PBQ, Universidade Estadual de Maringá, rmperalta@uem.br
} 
CORREA, V. G; TABADA, B. K; SPACK, K. C; CORRÊA, R. C. G; PERALTA, R. M.

\section{Introdução}

Ilex paraguariensis A. St. Hill (Aquifoliaceae), é uma planta nativa popular entre os habitantes do Paraguai, Uruguai e regiões da Argentina e Brasil da qual é obtida a erva mate. Com o uso de folhas e caules da árvore podem ser preparadas bebidas estimulantes com propriedades medicinais como o chimarrão (folhas verdes secas, preparado com água quente), tererê (folhas verdes secas, preparado com água fria) e chá mate (folhas tostadas, preparado com água quente) (BRACESCO et al., 2011; LIMA et al., 2014a) (Figuras 1 e 2).

Figura 1. Mate verde (esquerda) e mate tostado (direita) de Ilex paraguariensis
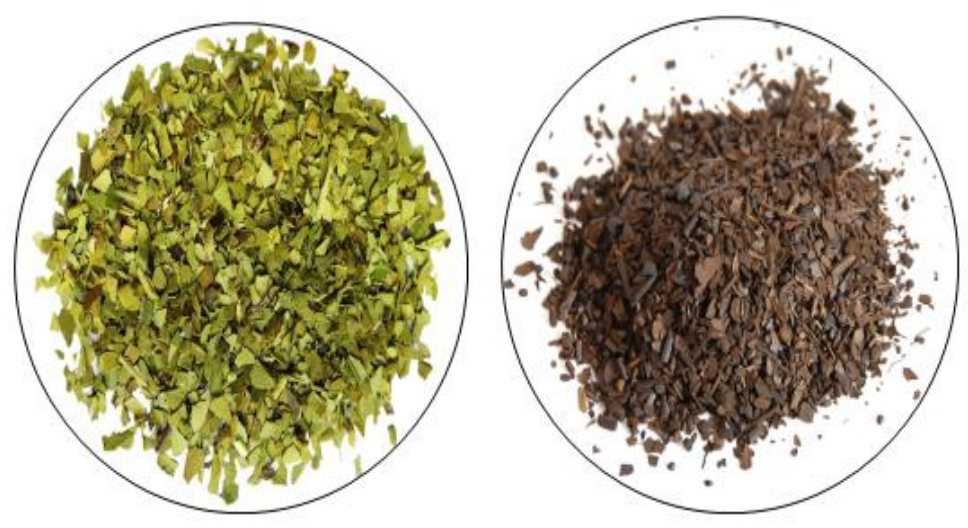

Figura 2. Principais bebidas à base de erva mate (Ilex paraguariensis)

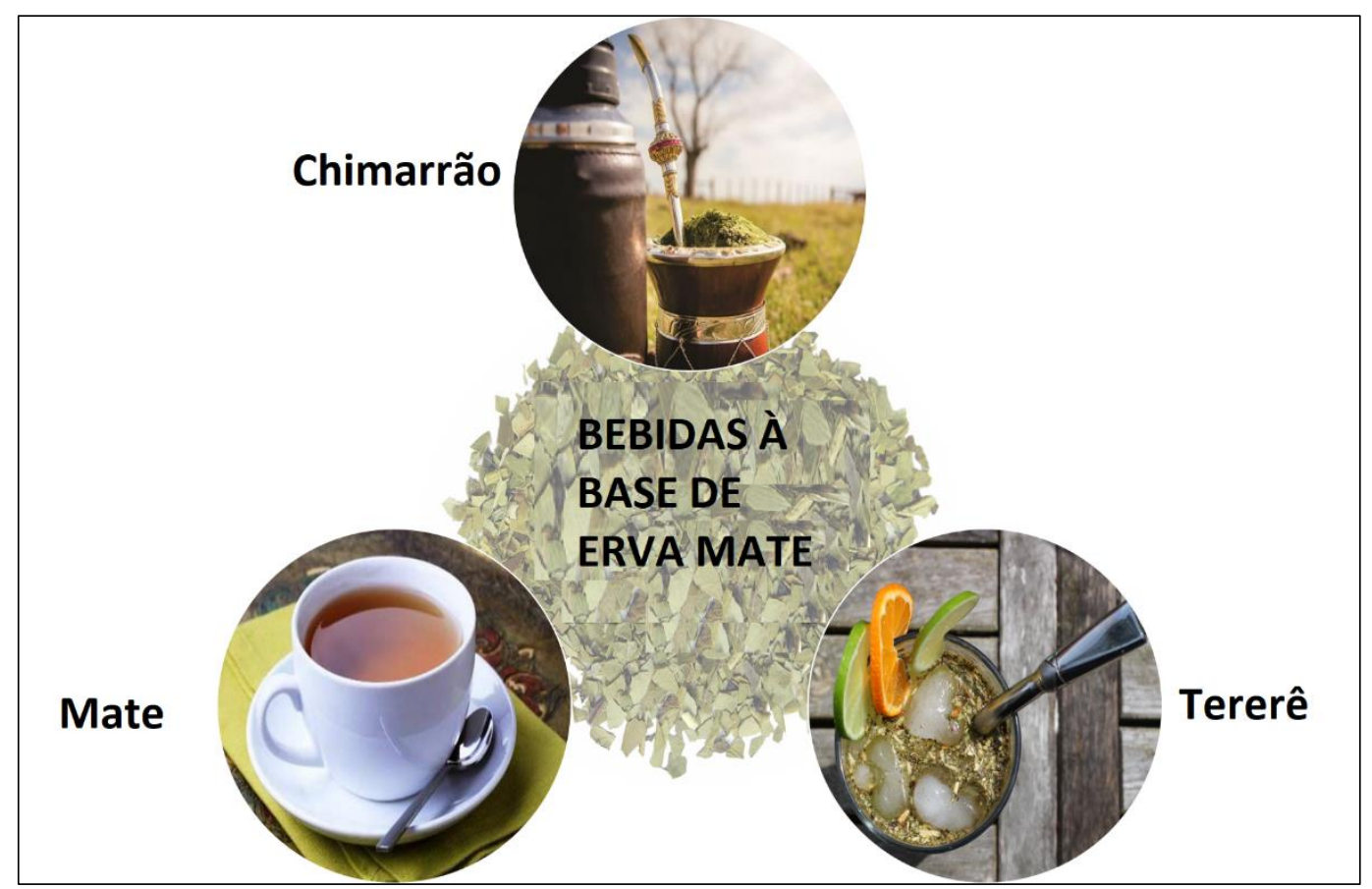

Fonte: CORREA et al., 2019 (modificado) 
O mate tem um papel social muito importante e o ato de oferecê-lo e compartilhá-lo tem conotações semelhantes às cerimônia do chá para algumas culturas orientais. O consumo per capta de erva mate chega a ser de 8-10 kg/hab/ano no Uruguai, 6,5 kg/hab/ano na Argentina e 3-5 kg/hab/ano no Sul do Brasil, estimando que nesses países o consumo de folhas secas da planta seja de 12 a 23 g/hab/dia (CORREA et al., 2019; CARDOZO JR; MORAND, 2016).

Além dos países da América do Sul, o consumo da planta tem alcançado interesse mundial. Outros países como Estados Unidos, Alemanha e Síria utilizam a Ilex paraguariensis A. St. Hil. para a produção de chás e bebidas energéticas. Mais recentemente o consumo tem se expandido para a Espanha, Itália, Austrália, França, Japão, Coreia e Rússia (CARDOZO JR; MORAND, 2016).

O consumo de produtos derivados da erva mate tem sido relacionado a benefícios à saúde como o tratamento da obesidade, melhora no perfil lipídico e na circulação sanguínea, (LIMA et al., 2014a; LIMA et al., 2014b; KIM et al., 2015; HECK; DE MEJÍA, 2007; SOUZA et al., 2015). Efeitos citotóxicos e atividade antiproliferativa de células cancerígenas, atividade antifúngica, anti-bacteriana, atividade anti-inflamatória e efeitos hepatoprotetores, neuroprotetores e antidepressivo tem também sido associados às bebidas à base da erva mate (DE MEJÍA et al., 2010; BURRIS et al., 2011).

Um paralelo interessante pode ser traçado entre Ilex paraguariensis (erva-mate) e Camellia sinensis (chá verde) (ASKARIPOUR, 2020). Ambos têm sido usados tradicionalmente para a preparação de bebidas estimulantes em dois continentes diferentes, Ásia e América do Sul. O chá verde ganhou, desde há muito, uma distribuição e aceitação quase universais, enquanto esse processo está no início para a erva mate. No entanto, os efeitos benéficos das bebidas contra vários distúrbios de saúde não são devidos aos mesmos bioativos. No chá verde, os bioativos pertencem à família das catequinas (epigalocatequina-3-galato (EGCG), epigalocatequina (EGC) e epicatequina-3-galato (ECG) são consideradas as moléculas ativas mais importantes (SERAFINI et al., 2011), enquanto para a erva mate, a família dos ácidos clorogênicos (ácido 3-O-cafeoilquínico, ácido 4-O-cafeoilquínico, ácido 5$O$-cafeoilquínico e o ácido 3,5-O-dicafeoilquínico) provavelmente são responsáveis por uma significativa parte das ações benéficas das bebidas (BRACESCO et al., 2011; SOUZA et al., 2015; CORREA et al., 2017; SILVEIRA et al., 2016; LIMA et al., 2014). Outros compostos presentes na erva mate são o ácido gálico, ácido cafeico, ácido siríngico, ácido ferúlico, ácido p-coumárico e rutina (CORREA et al., 2017; SILVEIRA et al., 2016; MURAKAMI et al., 2013). 
O reconhecimento das propriedades funcionais da erva mate despertou a atenção dos consumidores e vários produtos alimentícios tais como chocolates, barras de cereais, sorvetes, entre outros tem sido enriquecidos com seus extratos (Figura 3).

Figura 3. Produtos da área alimentícia enriquecidos com extratos de erva mate

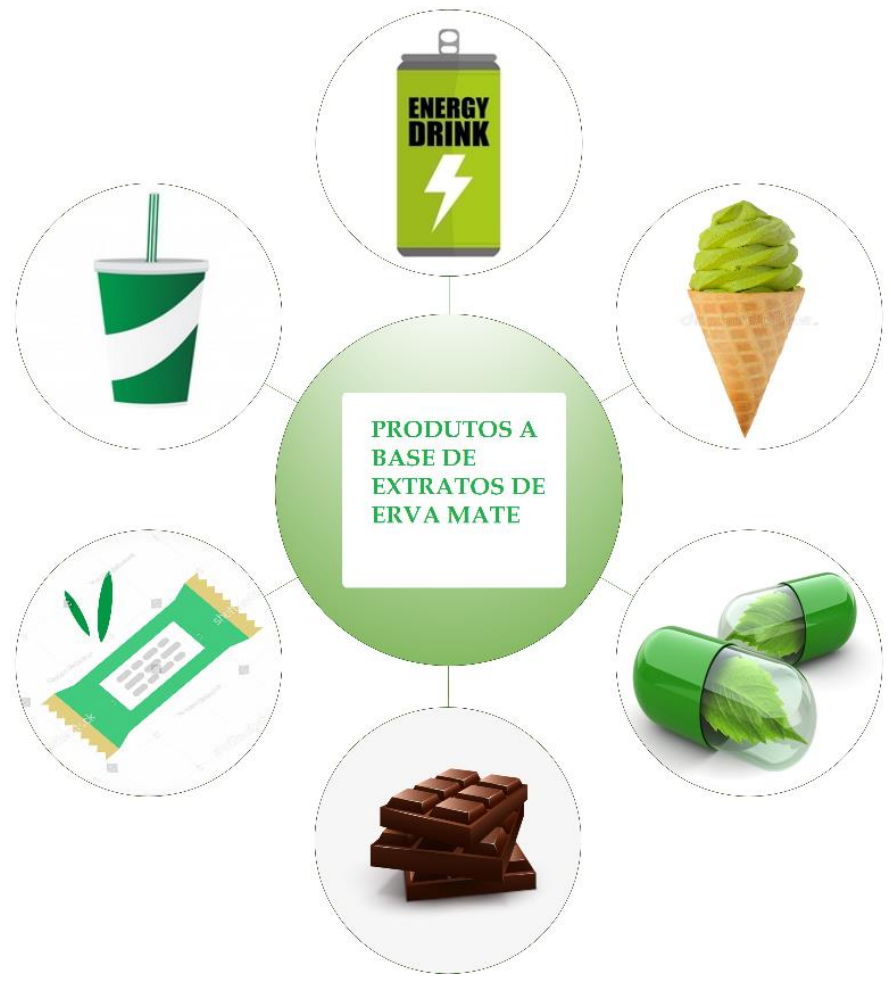

Fonte: CORREA et al., 2019 (modificado)

Estudos que mimetizam o processo de digestão têm demonstrado que os compostos bioativos da erva mate sofrem transformações durante a passagem pelas etapas do trato gastrointestinal, resultando em moléculas diferentes daquelas que são observadas no alimento ingerido (BOAVENTURA et al., 2015). As transformações ocorridas no trato gastrointestinal são decorrentes principalmente de condições fisiológicas como o pH e temperatura, ação das enzimas digestivas, tempo da digestão e pelo metabolismo da microbiota intestinal (CORREABETANZO et al., 2014; KOEHNLEIN et al., 2016). Cerca de um terço dos ácidos clorogênicos ingeridos são absorvidos a partir do intestino delgado, com uma possível contribuição do estômago; o restante atinge o intestino grosso e sofre alterações pela microbiota resultando em derivados $O$-metilados, sulfatados e glucorados, bem como em diidro metabolitos como ácido diidrocafeico (STALMACH et al., 2009; CORREA-BETANZO et al., 2014). 
Há nos dias atuais, uma crescente preocupação com a eficácia dos bioativos e muitos estudos buscam avaliar as perdas das propriedades funcionais dos alimentos durante os processos de extração, processamento, armazenamento e consumo (HENNING et al., 2014; ISOLABELLA et al., 2010; MACIAS-CORTES et al., 2020). Dentro deste contexto, a microencapsulação, um processo onde um material formador de parede é utilizado para recobrir os bioativos visando protege-los de condições adversas, vem sendo cada vez mais estudado e aplicado na área de alimentos (KUANG; OLIVEIRA; CREAN, 2010; VOLUC et al., 2019). Esta tecnologia pode ser aplicada em materiais sólidos, líquidos ou gasosos (AUGUSTIN \& HEMAR, 2008). Uma grande variedade de materiais de revestimento pode ser utilizada nas formulações. Dentre elas, citamos duas, a maltodextrose, um carboidrato nutritivo que na forma uma película protegendo o material volátil e mostra retenção na faixa de 65 a $80 \%$ do material e tem efeito antioxidante (ASCHERI et al., 2003), e o alginato de sódio, um polissacarídeo linear solúvel em água, extraído de diferentes tipos algas (ETCHEPARE et al., 2015). O alginato gelifica rapidamente na presença de íons cálcio sem alterações drásticas de temperatura, $\mathrm{pH}$ e pressão osmótica, conservando a atividade das moléculas e a viabilidade dos microrganismos.

Em um recente estudo realizado por nosso grupo foi observado que parte significativa dos compostos antioxidantes dos extratos da erva mate são perdidos durante a digestão gastrointestinal (CORREA et al. 2017). As maiores perdas foram dos ácidos 3,5-O-dicafeoilquínico e ácido 5-O-cafeoilquínico. Estas reduções causaram uma perda significativa da atividade antioxidante dos extratos. Considerando este fato, o objetivo deste trabalho foi avaliar uma provável ação protetora da microencapsulação nos bioativos antioxidantes dos extratos da erva mate submetidos ao processo de digestão gastrointestinal in vitro.

\section{Material e Métodos}

\section{Obtenção do extrato de erva mate para a microencapsulação}

O extrato de erva mate foi produzido a partir da erva adquirida no comércio de Maringá, PR. Para a extração dos compostos, $85 \mathrm{~g}$ da erva mate foram adicionados a 1,5 L de água destilada a $85^{\circ} \mathrm{C}$, permanecendo sob agitação por 5 minutos. Após o período, o material foi filtrado à vácuo, liofilizado e mantido a $-20^{\circ} \mathrm{C}$ até as análises.

\section{Quantificação de compostos fenólicos totais}

Os compostos fenólicos totais foram analisados conforme SINGLETON \& ROSSI (1965). Uma alíquota de cada amostra foi diluída convenientemente em um volume final de $2 \mathrm{~mL}$ com água 
destilada. Em seguida, adicionou-se 0,1 $\mathrm{mL}$ do reagente fenol Folin Ciocalteu e 0,3 $\mathrm{mL}$ de carbonato de sódio 1,9 M. As misturas permaneceram em repouso por 1 hora no escuro. As absorbâncias das amostras foram determinadas em espectrofotômetro no comprimento de onda $725 \mathrm{~nm}$ contra o branco. Os resultados foram expressos em equivalentes de ácido gálico (EAG).

\section{Determinação da atividade antioxidante pelo ensaio do poder redutor do íon ferro (FRAP)}

A atividade antioxidante foi avaliada pelo ensaio FRAP conforme descrito previamente (PULIDO, BRAVO, SAURA-CALIXTO, 2000). Resumidamente, $900 \mu \mathrm{L}$ de reagente FRAP foi adicionado a $90 \mu \mathrm{L}$ de água destilada e $30 \mu \mathrm{L}$ dos extratos (livres ou microencapsulados), do padrão TROLOX ou do branco (água). Após 30 min a $37^{\circ} \mathrm{C}$, as absorbâncias das amostras foram determinadas em espectrofotômetro a $595 \mathrm{~nm}$ contra o branco. Os resultados foram expressos em $\mu \mathrm{M}$ equivalente de TROLOX/mg de extrato.

\section{Processo de microencapsulação em maltodextrina e alginato de cálcio}

Para a microencapsulação, o extrato de erva mate foi ressuspenso em água e o material encapsulante (maltodextrina DE10 ou alginato de sódio em água) foram misturados na proporção de 1:1 (massa/massa) e deixados sob agitação por $30 \mathrm{~min}$. À mistura extrato-alginato de sódio adicionou-se gota a gota solução de cloreto de cálcio 0,2 M. A mistura foi mantida sob agitação por mais $30 \mathrm{~min}$. As misturas foram liofilizadas e mantidas à $-20^{\circ} \mathrm{C}$ até uso.

\section{Rendimento da microencapsulação}

O rendimento do produto (\%) foi calculado para cada experimento de microencapsulação utilizando a equação:

$$
\text { Rendimento }(\%)=\frac{\text { conteúdo em fenólicos totais do material encapsulado }}{\left(\frac{1}{2}\right) \text { conteúdo em fenólicos do extrato livre }} \times 100
$$

\section{Preparação das soluções de saliva artificial e dos fluídos gástrico e intestinal.}

As soluções de saliva artificial e dos fluídos gástrico e intestinal necessárias para a digestão gastrointestinal in vitro foram preparadas conforme previamente descrito (CORREA et al 2017). Resumidamente, a solução de saliva artificial foi preparada pela dissolução de $2,38 \mathrm{~g}$ $\mathrm{Na}_{2} \mathrm{HPO}_{4}, 0,19 \mathrm{~g}$ de $\mathrm{KH}_{2} \mathrm{PO}_{4}$ e $8 \mathrm{~g}$ de $\mathrm{NaCl}$ em $1 \mathrm{~L}$ de água destilada. $\mathrm{O} \mathrm{pH}$ da solução foi ajustado para 6,75 e adicionado alfa-amilase para obtenção de $200 \mathrm{U}$ de atividade da enzima. 
O fluído gástrico artificial foi preparado adicionando-se uma solução a 0,32\% de pepsina a uma solução $0,03 \mathrm{M}$ de $\mathrm{NaCl}, \mathrm{pH}$ 1,2. O fluído intestinal artificial foi preparado pela diluição de $0,05 \mathrm{~g}$ de pancreatina e $0,3 \mathrm{~g}$ de extrato de bile a $35 \mathrm{~mL}$ de $\mathrm{NaHCO}_{3} 0,1 \mathrm{M}$.

\section{Digestão gastrointestinal in vitro}

A digestão gastrointestinal in vitro foi realizada de acordo com metodologia previamente descrita (CORREA et al., 2017) (Figura 4). Para avaliar o comportamento dos materiais antes a após as etapas da digestão os grupos foram identificados como:

EEM-extrato de erva mate livre;

EEMOG-extrato de erva mate após a digestão oral e gástrica;

EEMOGI-extrato de erva mate após a digestão oral, gástrica e intestinal;

MCM-extrato de erva mate em microcápsulas de maltodextrina;

MCMOG- microcápsula de maltodextrina após a digestão oral e gástrica;

MCMOGI- microcápsula de maltodextrina após a digestão oral, gástrica e intestinal;

MCA- extrato de erva mate em microcápsulas de alginato de cálcio;

MCAOG- microcápsula de alginato de cálcio após a digestão oral e gástrica;

MCAOGI- microcápsula de alginato de cálcio após a digestão oral, gástrica e intestinal.

Ao final dos processos, todos os materiais foram liofilizados e armazenados a $-20{ }^{\circ} \mathrm{C}$.

Figura 4. Diagrama utilizado para digestão gastro-intestinal in vitro das amostras de extrato de erva mate livre e microencapsuladas.

\begin{tabular}{|l|l|}
\hline \multicolumn{1}{|c|}{ Diagrama da digestão in vitro } \\
\hline $1^{\mathrm{a}}$ Fase da digestão \\
$2^{\mathrm{a}}$ Fase da digestão
\end{tabular}

Fonte: CORREA et al., 2017 com modificações 


\section{Resultados e Discussão}

A Figura 5 mostra os aspectos dos extratos da erva mate após microencapsulação em maltodextrina e alginato de cálcio.

As eficiências de encapsulação foram avaliadas pela quantificação de fenólicos totais nos extratos livres e nos materiais microencapsulados. Os microencapsulados em maltodextrina e alginato mostraram uma eficiência próxima de 100\% (AHMADIAN; NIAZMAND; POURFARZARD, 2019; RIBEIRO et al., 2016).

Os três materiais (extrato de mate livre e os dois materiais microencapsulados) foram submetidos à digestão in vitro seguindo os passos descritos na Figura 4. Para metade dos materiais, a digestão foi interrompida após a fase gástrica, enquanto a outra metade foi submetida também à fase intestinal. Os materiais foram avaliados quanto ao teor em fenólicos totais (Figura 6) e atividade antioxidante pelo ensaio FRAP (Figura 7). Podemos observar que após a digestão gastrointestinal ocorreu uma redução de cerca de $30 \%$ no conteúdo em fenólicos totais e na atividade antioxidante dos extratos livres. A fase oral-gástrica foi a responsável por esta redução, considerando que, após a fase intestinal, não ocorreram novas reduções nos valores de fenólicos totais e atividade antioxidante.

Figura 5. Extrato de mate microencapsulado em maltodextrina (A) e alginato de cálcio (B)
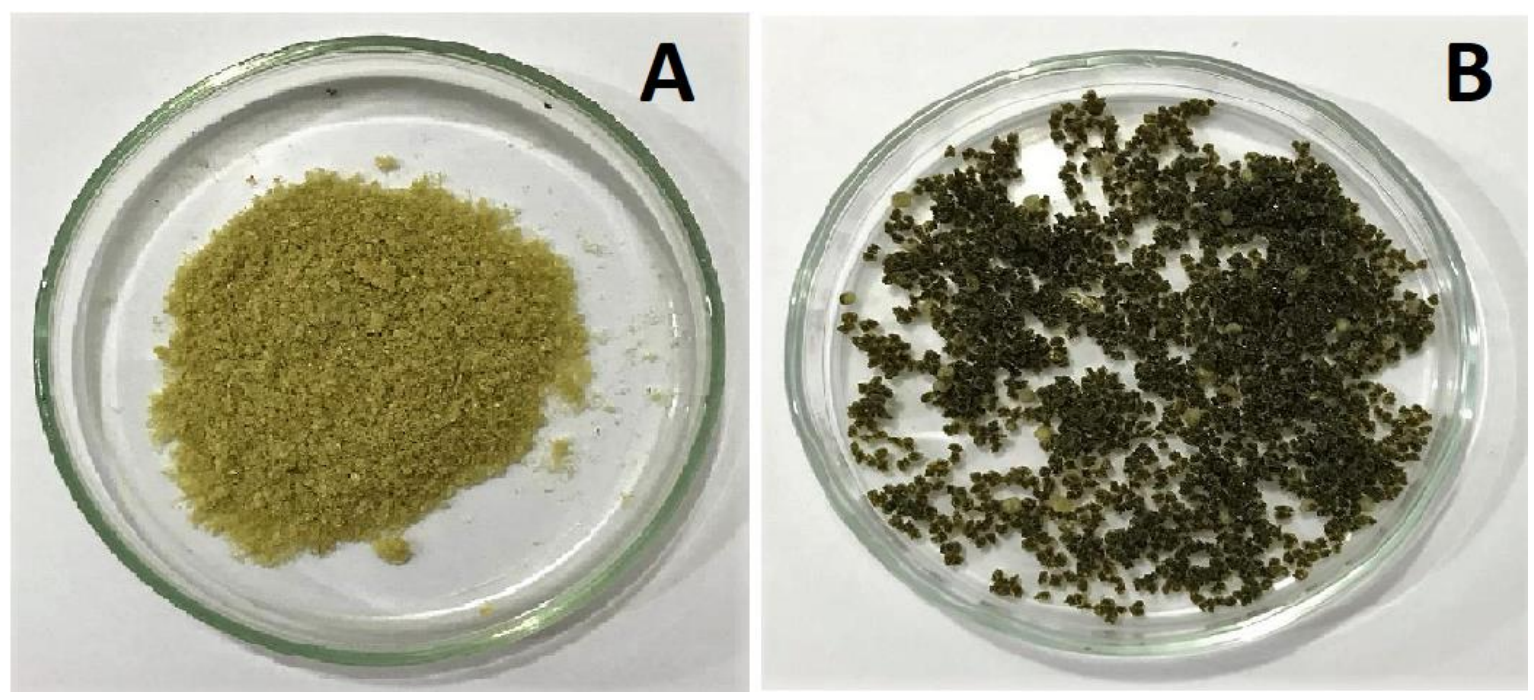

As análises indicaram uma efetiva liberação dos fenólicos microencapsulados do extrato da erva mate. Para os materiais microencapsulados, os teores em fenólicos totais foram significativamente superiores aos obtidos para os extratos brutos pós digestão gastrointestinal $(\mathrm{p} \leq 0,05)$, indicando efetiva proteção no ambiente ácido do estômago. Em relação à atividade 
antioxidante FRAP, entretanto, não foi encontrada significância estatística entre os extratos livres e microencapsulados ( $\mathrm{p} \geq 0,05)$, apesar de ser possível observar uma discreta tendência de redução das perdas das atividades antioxidantes liberadas pós digestão pelos materiais microencapsulados quando comparadas com as perdas dos extratos livres. Os resultados demonstram que os dois tipos de microencapsulação (em maltodextrina e em alginato) tiveram as mesmas eficiências protetoras quando submetidas à digestão in vitro.

Microencapsulações dos extratos de mate já foram realizadas com sucesso e tornaram o produto mais resistente ao calor e ao armazenamento (NEGRÃO-MURAKAMI et al., 2017; NUNES et al., 2015). Até o momento, entretanto, microencapsulação do mate e seu efeito protetor reduzindo as perdas durante a digestão gastrointestinal não foi estudado. Muitos fenólicos são sensíveis às variações de pH (FRIEDMAN; JÜRGENS, 2000), incluindo os ácidos clorogênicos, principal família de antioxidantes do mate (GONÇALVES et al., 2017). Estudos realizados com diferentes extratos vegetais com propriedades antioxidantes, sugerem que a microencapsulação protege os bioativos dos ambientes inóspitos encontrados no trato gastro-intestinal, como mudanças no pH e ação das enzimas digestivas. Alguns exemplos são o extrato de pétalas de açafrão encapsulado em uma mistura de maltodextrina e pectina (AHMADIAN; NIAZMAND; POURFARZARD, 2019), extrato de resíduo de pimenta (Capsicum annuum L) encapsulado em proteína de soro de leite (VULIC et al., 2019) e o extrato de polpa de alfarroba, encapsulado em metil-celulose (YDJEDD et al., 2017). Outros exemplos onde a microencapsulação protegeu os bioativos dos extratos vegetais podem ser encontrados em uma revisão recente que aborda este tema (PEANPARKDEEA; IWAMOTO, 2020). 
Figura 6. Compostos fenólicos totais após as etapas da digestão gastrointestinal. EEMextrato de erva mate livre; EEMOG- extrato de erva mate após a digestão oral e gástrica; EEMOGI- extrato de erva mate após a digestão oral, gástrica e intestinal; MCM- extrato de erva mate em microcápsulas de maltodextrina; MCMOG- microcápsula de maltodextrina após a digestão oral e gástrica; MCMOGI- microcápsula de maltodextrina após a digestão oral, gástrica e intestinal; MCA- extrato de erva mate em microcápsulas de alginato de cálcio; MCAOG- microcápsula de alginato de cálcio após a digestão oral e gástrica; MCAOGImicrocápsula de alginato de cálcio após a digestão oral, gástrica e intestinal.Não há diferença estatística entre as médias com letras iguais $(n=3)(p<0,05)$ de acordo com o teste de NewmanKeuls.

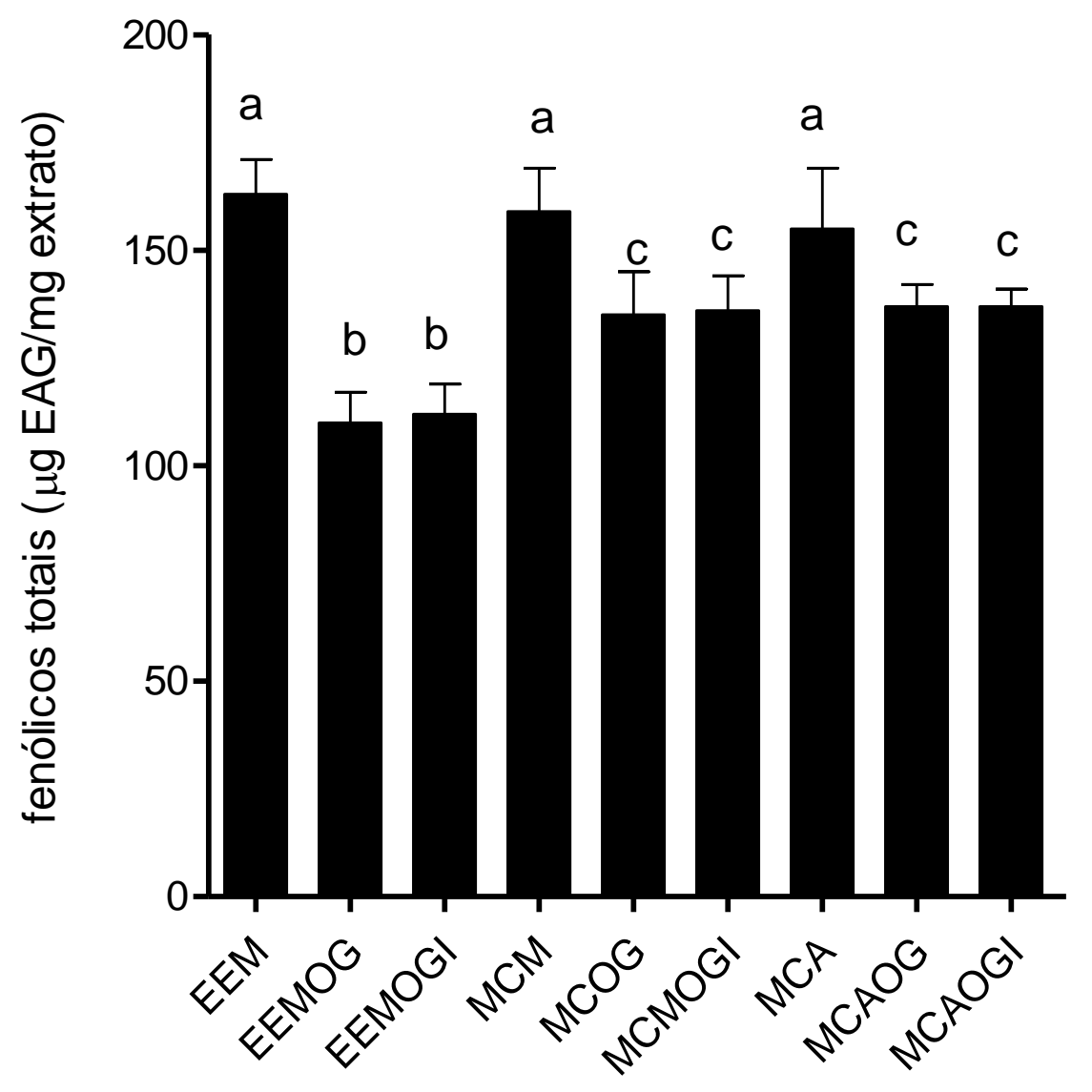


Figura 7. Atividade antioxidante avaliada pelo ensaio FRAPA após as etapas da digestão gastrointestinal. EEM- extrato de erva mate livre; EEMOG- extrato de erva mate após a digestão oral e gástrica; EEMOGI- extrato de erva mate após a digestão oral, gástrica e intestinal; MCM- extrato de erva mate em microcápsulas de maltodextrina; MCMOGmicrocápsula de maltodextrina após a digestão oral e gástrica; MCMOGI- microcápsula de maltodextrina após a digestão oral, gástrica e intestinal; MCA- extrato de erva mate em microcápsulas de alginato de cálcio; MCAOG- microcápsula de alginato de cálcio após a digestão oral e gástrica; MCAOGI- microcápsula de alginato de cálcio após a digestão oral, gástrica e intestinal.Não há diferença estatística entre as médias com letras iguais $(n=3)$ $(\mathrm{p}<0,05)$ de acordo com o teste de Newman-Keuls.

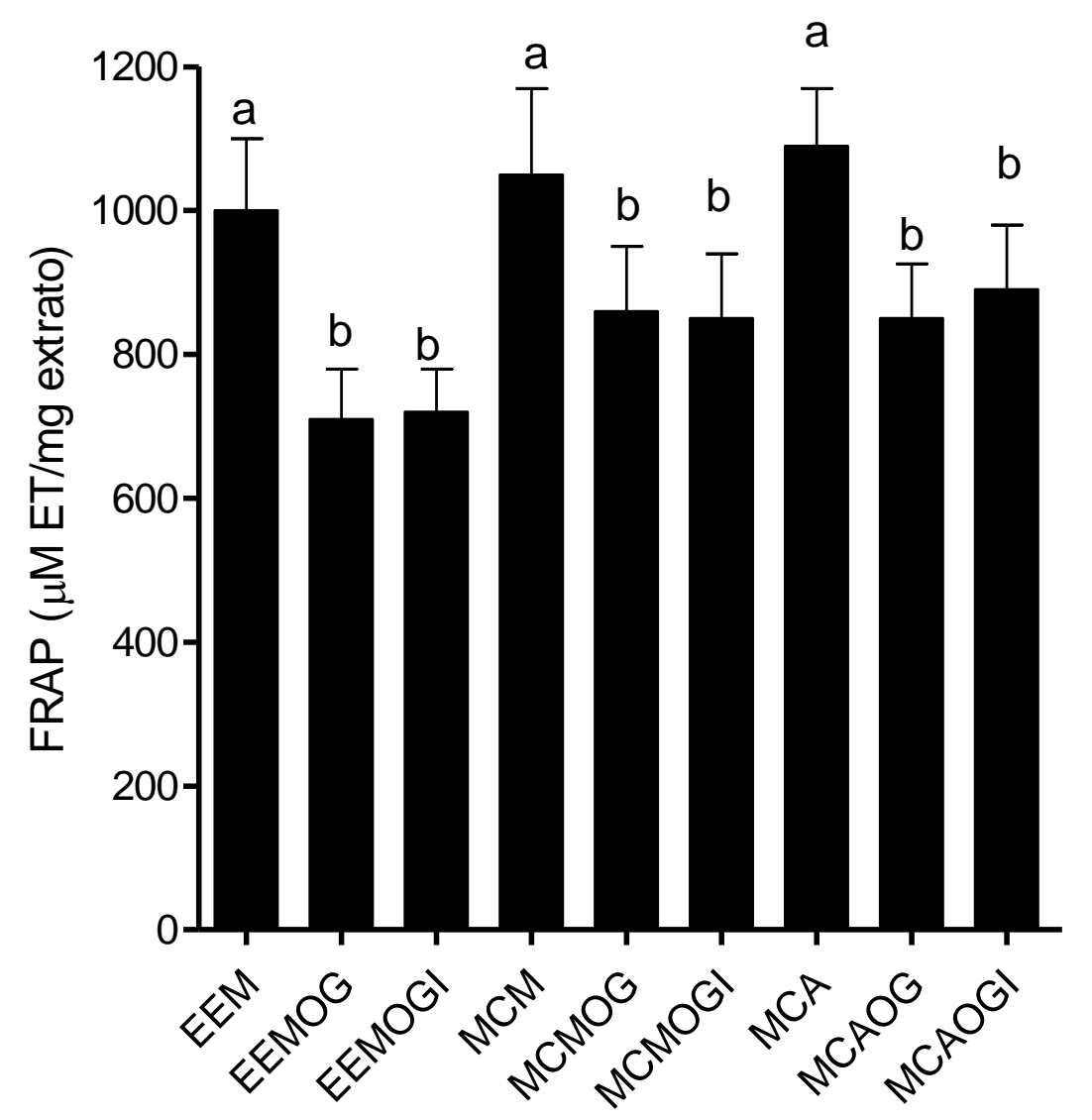

\section{Conclusões}

Neste trabalho, os extratos de erva mate ricos em compostos fenólicos antioxidantes, principalmente da família dos ácidos clorogênicos, foram microencapsulados com sucesso em malltodextrina e alginato de cálcio. A estabilidade ao processo de digestão gastrointestinal in vitro dos extratos livre e microencapsulados foi avaliada utilizando-se como parâmetros o teor em compostos fenólicos totais e a atividade antioxidante pelo método FRAP. Os resultados 
obtidos sugerem que as duas microencapsulações mostraram uma leve tendência de proteção dos bioativos antioxidantes dos extratos. Outros agentes encapsulantes e outras condições de microencapsulação estão sendo testadas em nosso laboratório visando melhorar a eficiência do processo.

\section{Agradecimentos}

Os autores agradecem o apoio financeiro da Coordenação de Aperfeiçoamento de Pessoal de Nível Superior- CAPES, Conselho Nacional de Desenvolvimento Científico e TecnológicoCNPq e Universidade Estadual de Maringá-UEM para a realização deste trabalho

\section{Referências}

AHMADIAN, Z., NIAZMAND, R., POURFARZARD, A. Microencapsulation of saffron petal phenolic extract: their characterization, in vitro gastrointestinal digestion, and storage stability. Journal of Food Science, v. 84, pp. 2745-2757, 2019

ASCHERI, D. P. R. et al. Microencapsulation of orange essential oil: Wall material selection. Food Science and Technology, v. 23, p. 1-6, 2003.

ASKARIPOUR, D. Green Tea vs Yerba Mate - Circle of Drink. Acesso em julho de 2020. https://circleofdrink.com/green-tea-vs-yerba-mate.

AUGUSTIN, M. A.; HEMAR, Y. Nano- and micro-structured assemblies for encapsulation of food ingredients. Chemical Society Reviews, v. 38, pp. 902-912, 2009

BOAVENTURA, B. C. B. et al. Effect of in vitro digestion of yerba mate (Ilex paraguariensis A. St. Hil.) extract on the cellular antioxidant activity, antiproliferative activity and cytotoxicity toward HepG2 cells. Food Research International, v. 77, pp. 257-263, 2015

BRACESCO N. et al., Recent advances on Ilex paraguariensis research: Minireview. Journal of Ethnopharmacology, v. 136, pp. 378-384, 2011

BURRIS, K. P. et al. Antimicrobial activity of yerba mate (Ilex paraguariensis) aqueous extracts against Escherichia coli O157:H7 and Staphylococcus aureus. Journal of Food Science, v. 76, pp. 456-462, 2011

CARDOZO JR, E. L.; MORAND, C. Interest of mate (Ilex paraguariensis A. St.-Hil.) as a new natural functional food to preserve human cardiovascular health-A review. Journal of Functional Foods, v. 21, p. 440-454, 2016.

CORREA, V. G. et al. . Effects of in vitro digestion and in vitro colonic fermentation on stability and functional properties of yerba mate (Ilex paraguariensis A. St. Hil.) beverages. Food chemistry, v. 237, p. 453-460, 2017.

CORREA, V. G. et al. Ilex paraguariensis A. St. Hil): a promising adjuvant in the treatment of diabetes, obesity, and metabolic syndrome. In: Mohammad Ullah; Aamir Ahmad. (Org.). 
Nutraceuticals and natural product derivatives: disease prevention \& drug discovery. 1ed.Hoboken, New Jersey, USA: Wiley-Blackwell, 2019, v. 1, p. 167-182.

CORREA-BETANZO, J. et al. Stability and biological activity of wild blueberry (Vaccinium angustifolium) polyphenols during simulated in vitro gastrointestinal digestion. Food Chemistry, v. 165, p. 522-531, 2014.

DE MEJÍA, E. G. et al. Yerba mate tea (Ilex paraguariensis): Phenolics, antioxidant capacity and in vitro inhibition of colon cancer cell proliferation. Journal of Functional Foods, v. 2, n. 1, p. 23-34, 2010.

ETCHEPARE, M. A. et al. Microencapsulation of probiotics using sodium alginate. Ciência Rural, v. 45, pp. 1319-1326, 2015

FRIEDMAN, M.; JÜRGENS, H. S. Effect of pH on the stability of plant phenolic compounds. Journal of Agricultural and Food Chemistry, 48, pp. 2101-2110, 2000

GONÇALVES, B. et al. Microencapsulation of a natural antioxidante from coffee-chlorogenic acid (3-caffeoyl quinic acid). Food Bioprocess Technology, v. 10, pp. 1521-1530, 2017

HECK, C.I.; DE MEJIA, E. G. Yerba mate tea (Ilex paraguariensis): a comprehensive review on chemistry, health implications, and technological considerations. Journal of Food Science, 72, pp. 138-151, 2007

HENNING, S. M. et al., Variability in the antioxidant activity of dietary supplements from pomegranate, milk thistle, green tea, grape seed, goji, and acai: effects of in vitro digestion. Journal of Agricultural and Food Chemistry, 62, pp. 4313-4321, 2014

ISOLABELLA, S. et al. Study of the bioactive compounds variation during yerba mate (Ilex paraguariensis) processing. Food Chemistry, 122, pp. 695-699, 2010

KIM, S.Y. et al. Anti-obesit effects of yerba mate (Ilex paraguariensis): A randomized, doubleblind, placebo-controlled clinical trial. BMC Complementary and Alternative Medicine, 15, pp. 338-345, 2015

KOEHNLEIN, E. A. et al. Analysis of a whole diet in terms of phenolic content and antioxidant capacity: Effects of a simulated gastrointestinal digestion. International Journal of Food Science and Nutrition, 67, pp. 614-623, 2016

KUANG, S. S.; OLIVEIRA, J. C.; CREAN, A. M. Microencapsulation as a tool for incorporating bioactive ingredients into food. Critical Rreviews in Food Science and Nutrition, v. 50, n. 10, p. 951-968, 2010.

LIMA, J.D.P. et al. Distribution of major chlorogenic acids and related compounds in Brazilian green and toasted Ilex paraguariensis (Maté) leaves. Journal of Agricultural and Food Chemistry, v. 64, pp. 2361-2370, 2016

LIMA, N. D. S. et al. Effec, ts of Ilex paraguariensis (yerba mate) treatment on leptin resistance and inflammatory parameters in obese rats primed by early weaning. Life Sciences, 115, pp. 29-35, 2014a 
LIMA, N.D.S. et al. Ilex paraguariensis (yerba mate) improves endocrine and metabolic disorders in obese rats primed by early weaning. European Journal of Nutrition, 53, pp. 73$82,2014 b$

MACIAS-CORTES, E. et al. Microencapsulation of phenolic compounds: Technologies and novel polymers. Revista Mexicana de Ingeniria Quimica, v. 19, pp. 491-521, 2020

MURAKAMI, A.N.N. et al. Concentration of biologically active compounds extracted from Ilex paraguariensis St. Hil. by nanofiltration. Food Chemistry, 141, pp. 60-65, 2013

NEGRÃO-MURAKAMI, A. N. et al. Influence of DE-value on maltodextrin on the physicochemical properties, antioxidante activity, and storage stability of spray dried concentrated mate (Ilex paraguariensis A. St. Hill). LWT- Food Science and Technology, v. 79 , pp. 561-567, 2017

NUNES, G. L. et al. Microencapsulation of freeze concentrated Ilex paraguariensis extract by spray drying. Journal of Food Engineering, v. 151, pp. 60-68, 2015

PEANPARKDEEA, M.; IWAMOTO S. encapsulation for improving in vitro gastrointestinal digestion of plant polyphenols and their applications in food products Food Reviews International, https://doi.org/10.1080/87559129.2020.1733595, 2020

PULIDO, R.; BRAVO, L.; SAURA-CALIXTO, F. Antioxidant activity of dietary polyphenols as determined by a modified ferric reducing/antioxidant power assay. Journal of Agricultural and Food Chemistry, v. 48, n. 8, p. 3396-3402, 2000.

RIBEIRO, A. et al. Rosemary extracts in functional foods: extraction, chemical characterization and incorporation of free and microencapsulated forms in cottage cheese. Food \& Function, v. 7, pp. 2185-2196, 2016

SERAFINI, M et al. 2011. Herbal medicine: biomolecular and clinical aspects, Herbal Medicine: Biomolecular and Clinical Aspects , BENZIE, F.F.; WACHTEL-GALOR, S. CRC Press, Boca Raton-USA.

SILVEIRA, A.D. et al., Phenolic compounds from yerba mate based beverages - A multivariate optimisation. Food Chemistry, v. 190, pp. 1159-1167, 2016

SINGLETON, V.L., ROSSI, J.A. Colorimetry of total phenolics with phosphomolybdicphosphotungstic acid reagents. American journal of Enology and Viticulture, v. 16, n. 3, p. 144-158, 1965.

SOUZA, A.H.P. et al. Phytochemicals and bioactive properties of Ilex paraguariensis: an invitro comparative study between the whole plant, leaves and stems. Food Research International, 78, pp. 286-294, 2015

STALMACH, A. et al. Bioavailability of chlorogenic acids following acute ingestion of coffee by humans with an ileostomy. Archives of Biochemistry and Biophysics, 501, pp. 98-105, 2010

YDJEDD, S. et al. Eff ect of in vitro gastrointestinal digestion on encapsulated and nonencapsulated phenolic compounds of carob (Ceratonia siliqua L.) pulp extracts and their antioxidant capacity. Journal of Agricultural and Food Chemistry, v. 65, pp. 827-835, 2017 
CORREA, V. G; TABADA, B. K; SPACK, K. C; CORRÊA, R. C. G; PERALTA, R. M.

VULIC, L. et al. Bioavailability and bioactivity of encapsulated phenolics and carotenoids isolated from red pepper waste. Molecules v. 24, pp. 2837-2847, 2019 